\title{
NOTÓRIO SABER PARA OS(AS) MESTRES(AS): CAMINHOS PARA 0 RECONHECIMENTO INSTITUCIONAL DOS SABERES TRADICIONAIS
}

\author{
BRUNO GOULART ${ }^{1}$
}

\begin{abstract}
RESUMO
Recentemente, temos visto nas universidades públicas brasileiras o reconhecimento institucional dos mestres e mestras dos saberes tradicionais, por meio do título do Notório Saber. Esse movimento está relacionado à disseminação dos conceitos de mestres e mestras nas políticas culturais e ao surgimento de projetos e propostas de inclusão epistêmica no ensino superior. Este artigo apresenta um levantamento e reflexão inicial sobre esse processo, procurando contextualizar e refletir sobre os caminhos que algumas universidades têm adotado para reconhecer os mestres e mestras com o Notório Saber. Ao final, será feita uma exposição sobre a experiência de redação da minuta do Notório Saber na UNILAB e sobre as particularidades desse processo numa universidade com apenas uma década, com foco na internacionalização e interiorização e sede num estado, o Ceará, com políticas pioneiras voltadas para os mestres e mestras.
\end{abstract}

\section{PALAVRAS-CHAVES}

Mestres(as) dos Saberes Tradicionais; Notório Saber; Universidade Pluriepistêmica; UNILAB.

\section{NOTORIOUS KNOWLEDGE TO THE MASTERS OF THE TRADITION: INSTITUTIONAL RECOGNITION OF THE TRADITIONAL KNOWLEDGES}

\begin{abstract}
Recently in Brazilians public universities the institutional recognition of masters of the traditional knowledge, through the title of Notorious Knowledge, has become a reality. This movement is associated to the emergence of the concept of masters of traditional knowledge in cultural policies and of projects that aim the epistemic inclusion in higher education. This article presents an initial survey of these discussions, seeking to contextualize and reflect on the paths that some universities have taken to recognize masters of traditional knowledge with the Notorious Knowledge tittle. Further, we present a discussion of the Notorious knowledge experience at UNILAB, and of the particularities of this process in an university with only a decade of existence, with focus on internationalization and interiorization, and headquarters in Ceará state, a pioneering in policies aimed to masters of traditional knowledge.
\end{abstract}

\section{KEYWORDS}

Masters of traditional knowledge; Notorious Knowledge tittle; Pluriepistemic University; UNILAB.

\section{NOTOIRE SAVOIR POUR LES MAÎTRES DES TRADITIONS: RECONNAISSANCE INSTITUTIONNEL DES}

\section{SAVOIRS TRADITIONNELS}

\begin{abstract}
RÉSUMÉ
Nous avons récemment expérimenté dans les universités publiques brésiliennes la reconnaissance institutionnelle des maîtres des savoirs traditionnels, à travers un titre appelé Notoire Savoir. Ce mouvement est lié à la diffusion des concepts de maîtres dans les politiques culturelles et l'émergence de projets d'insertion
\end{abstract}

\footnotetext{
${ }^{1}$ Professor do Instituto de Humanidades da Universidade da Integração Internacional da Lusofonia Afro-brasileira.
} 
épistémiques dans l'enseignement supérieur. Cet article présente une première réflexion sur ce processus et cherche à mettre en contexte et à réfléchir aux manières adoptées par quelques universités afin de reconnaître les maîtres avec ce titre de Notoire Savoir. À la fin, une réflexion sera faite sur l'expérience d'écriture du projet de création du titre de Notoire Savoir à l'UNILAB et les particularités de ce processus dans une université comptant seulement une décennie, axée sur l'internationalisation et l'intériorisation et ayant son siège à Ceará, un état pionnier dans les politiques destinées aux maîtres des savoirs traditionnels.

\section{MOTS-CLÉS}

Maîtres des savoirs traditionnels; Notoire Savoir; Université Pluriépistémique; UNILAB.

\section{NOTORIO SABER PARA LOS MAESTROS TRADICIONALES: RECONOCIMIENTO INSTITUCIONAL DE LOS SABERES TRADICIONALES}

\section{RESUMEN}

Recientemente, hemos experimentado en las universidades públicas brasileñas el reconocimiento institucional de los(las) maestros(as) de los saberes tradicionales, a través del título de Notorio Saber. Este movimiento está relacionado con la difusión de conceptos de maestros tradicionales en las políticas culturales y con el surgimiento de proyectos de inclusión epistémica en la educación superior. Este artículo presenta un primer recorrido y una reflexión sobre este proceso, buscando contextualizar y reflexionar sobre los caminos tomados en algunas universidades para reconocer a estos/as maestros/as con el Notorio Saber. Aún, se hará una reflexión sobre la experiencia de redacción de la propuesta de creación de una resolución del Notorio Saber en UNILAB y sobre las particularidades de este proceso en una universidad con solo una década de existencia, con enfoque en la internacionalización e interiorización, y sede en la provincia del Ceará, un estado con políticas pioneras dirigidas a maestros de los saberes tradicionales.

\section{PALABRAS-CLAVE}

Maestros de los saberes tradicionales; Notorio Saber; Universidad Pluriepistémica; UNILAB. 
Historicamente os ditos saberes tradicionais foram deslegitimados e marginalizados pelas instituições formais de ensino, e figuraram nesses espaços muitas vezes apenas como objetos ou temas de pesquisa. Em contraste, na última década, temos a criação nas universidades públicas de instrumentos para o reconhecimento institucional dos detentores desses saberes, por meio do título do Notório Saber. Esse movimento, porém, não é isolado, e está relacionado com outros fatores e experiências recentes, como a disseminação dos conceitos de mestres e mestras tradicionais nas políticas públicas culturais e o surgimento de projetos e propostas de inclusão desses sujeitos e seus saberes no ensino superior.

Em meio a esse contexto, no final do primeiro semestre de 2020 fui convidado pela Coordenadoria de Arte e Cultura, vinculada à Pró-reitoria de Extensão, a integrar uma comissão² para a realização de estudos técnicos de viabilização do reconhecimento do notório saber dos mestres da cultura popular na Universidade Internacional da Lusofonia Afro-Brasileira. A partir dessa pesquisa, a comissão foi encarregada de elaborar uma minuta sobre o Notório Saber que contemplasse os mestres e mestras das culturas, a ser apresentada para a Reitoria e o Conselho de Ensino, Pesquisa e Extensão. A PROEX então pautou a votação da minuta no CONSEPE, onde a resolução foi aprovada em fevereiro de 2021 de forma unânime.

Com base nessa experiência, este artigo apresenta um levantamento e reflexão sobre o processo de reconhecimento dos mestres e mestras nas universidades brasileiras por meio do título de Notório Saber. O objetivo é contextualizar, refletir e problematizar os caminhos que algumas universidades têm adotado para reconhecer os mestres e mestras com o Notório Saber. Ao final, será feita uma exposição sobre a redação da minuta do Notório Saber na UNILAB, seus potenciais desdobramentos e as particularidades desse processo numa universidade relativamente recente (completou 10 anos em 2020) com foco na internacionalização e interiorização e sede num estado, o Ceará, com políticas pioneiras voltadas para os mestres e mestras.

\section{Patrimônio imaterial, Tesouros humanos Vivos e 0 conceito de Mestres e MESTRAS DAS CULTURAS E DOS SABERES}

O surgimento do conceito de patrimônio imaterial e sua disseminação nas últimas décadas levaram a novos entendimentos, conceitos e desenhos das políticas patrimoniais. Nesse sentido, a categoria de patrimônio imaterial é uma consequência da crítica à noção

\footnotetext{
2 Além do autor deste artigo, a comissão foi composta pelos professores Ricardo Nascimento, coordenador de Arte e Cultura da PROEX/UNILAB, e Eduardo Gomes Machado, do curso de Licenciatura em Sociologia, além da técnica Maria do Socorro Maia Silva.
} 
eurocêntrica de patrimônio - associada aos grandes monumentos; a edificações com arquiteturas exemplares de períodos históricos; aos bens culturais das elites econômicas, sociais e culturais. Conceitualmente, o patrimônio imaterial passa a designar línguas, rituais, formas de expressão, saberes, ofícios e mesmo pessoas. Do ponto de vista da política de preservação, agora, mais do que no bem em si, o foco se volta para a salvaguarda dos processos que permitem a existência e continuidade social de determinada manifestação cultural.

É em meio a esses novos entendimentos e procedimentos que surge a noção de tesouros vivos, conceito que designa aqueles sujeitos referências nos saberes relacionados a determinadas práticas culturais e responsáveis por guardar, criar e transmitir esses saberes. Foi por meio desse entendimento que a UNESCO, em 1993, elaborou um guia para que seus países membros criassem uma política de proteção a tais "tesouros humanos vivos".

A inspiração para essa política veio de alguns países asiáticos que já adotavam entendimentos similares. É o caso do Japão, que desde 1950 tem ações e políticas voltadas para os detentores do saber-fazer de técnicas essenciais para expressões importantes do patrimônio cultural imaterial. Em 1964, a então República da Coreia também cria um sistema de proteção e de transmissão do patrimônio cultural imaterial para as gerações seguintes, tendo como foco esses tesouros vivos. Nas Filipinas, na década de 1970, o governo passa a conceder honras e privilégios aos artistas nacionais e, posteriormente, para os sujeitos considerados referências das tradições locais. Na Europa, o país pioneiro na implementação dessa categoria nas polícias patrimoniais foi a França, que em 1994 desenvolveu a política dos Mestres da Arte, com a missão de transmitir os saberes e técnicas desses mestres para as novas gerações, por meio da distribuição de bolsas para os mestres chapeleiros, do restauro, alfaiates, artesãos etc. (ABREU, 2009).

No Brasil, a noção de tesouros vivos vai sendo incorporada a partir dos anos 2000, com a criação de leis estaduais de proteção e valorização dos tesouros vivos - na Bahia, em Minas Gerais, em Alagoas, na Paraíba e no Ceará -, e com uma proposta de criação da lei federal dos mestres, além de editais e ações voltadas para esses sujeitos. No nosso país, o conceito de tesouros vivos se torna sinônimo de mestres ou mestras dos saberes e/ou culturas tradicionais - sendo esse último conceito bem mais difundido do que o primeiro.

O adjetivo tradicional da categoria mestre(a), que encontramos aqui, se relaciona com a trajetória de outro conceito, o de "cultura tradicional". Culturas tradicionais seriam uma metamorfose de povos e comunidades tradicionais (ALMEIDA; CUNHA, 2009), e designam as práticas culturais desses coletivos. Segundo Almeida e Cunha (2009), a nomenclatura tradicionais está em metamorfose e tem um potencial inclusivo, abarcando povos indígenas, extrativistas, ribeirinhos, quilombolas, expressões das culturas populares, etc. (ALMEIDA; CUNHA, 2009). É importante destacar também a relação que o termo tradicional adquire 
com o de patrimônio imaterial. Nesse sentido, os bens imateriais que têm sido objeto das políticas públicas patrimoniais são aqueles geralmente identificados como pertencentes ao universo da cultura popular e tradicional (IKEDA, 2013).

Apesar de amplamente difundido, cabe destacar que o termo mestres e mestras dos saberes e culturas tradicionais é uma categoria de política pública. Isso significa dizer que nem sempre as pessoas que chamamos de mestres(as) são assim nomeadas em suas comunidades, coletivos e agrupamentos. No universo da capoeira, por exemplo, o termo é similar, como quando chamamos de mestre(a) de capoeira aquele(a) que detém e transmite os saberes de sua escola ou linhagem. Porém, no universo do Candomblé falamos em mãe de santo e pai de santo, ou lalorixá e Babalorixá; no congado, falamos em capitão ou capitã, etc. Nesse sentido, mestres(as) tradicionais é uma categoria que abarca aquelas pessoas que são referência em determinadas áreas dos saberes e culturas, responsáveis por guardar, criar e transmitir esses saberes para seus coletivos e comunidades.

Um dos primeiros usos do termo no âmbito da política pública foi com a Lei $n^{\circ}$ 13.351, de 22 de agosto de 2003, que institui o Registro dos Mestres da Cultura Tradicional Popular do Estado do Ceará. Tratado como um conceito sinônimo de Tesouro Vivo, mestre(a) é definido na lei como "a pessoa natural que tenha os conhecimentos ou as técnicas necessárias para a produção e preservação da cultura tradicional popular de uma comunidade estabelecida no Estado do Ceará" (CEARÁ, 2003). A lei, ao reconhecer (diplomar é a categoria que aparece na Lei) determinada pessoa como mestre(a), contempla o detentor do título com um auxílio financeiro mensal. Em 2006 essa lei foi substituída pela Lei 13.842/2006, que institui o registro dos "tesouros vivos da cultura" no estado do Ceará e dá outras providências. Apesar de não fazer referência ao termo mestre, este já havia se popularizado no estado ${ }^{3}$ e o entendimento de tesouros vivos da cultura é semelhante ao que é definido enquanto mestre na lei de 2003. Entre os requisitos colocados para ser considerado tesouro vivo da cultura está "comprovar a existência e a relevância do saber ou do fazer"; "ter o reconhecimento público"; "deter a memória indispensável à transmissão do saber ou do fazer"; "propiciar a efetiva transmissão dos conhecimentos objeto do inciso anterior" (CEARÁ, 2006).

Para efeitos do Projeto de Lei 1.176-B/2011 (Lei dos mestres) em tramitação no congresso nacional, que propõe instituir um programa de proteção aos mestres e mestras dos saberes e fazeres tradicionais, a categoria é definida como

"[...] pessoas que se expressam através de diversas linguagens artísticas, ritos sagrados e festas comunitárias, brasileiros natos ou naturalizados, cuja vida e obra foram dedicadas à proteção, promoção e desenvolvimento da cultura tradicional brasileira; de sabedoria notória, reconhecida entre seus pares e por especialistas; com longa

\footnotetext{
${ }^{3}$ Tanto é que a Lei de 2006 continua sendo referida popularmente como a Lei dos Mestres.
} 
permanência na atividade e capacidade de transmissão dos conhecimentos artísticos e culturais" (BRASIL, 2011, p. 3).

No Prêmio Cultura Popular, do hoje extinto Ministério da Cultura, mestre(a) é entendido como "pessoa que tem grande experiência e conhecimento dos saberes e fazeres populares"; que se dedica "às expressões culturais populares"; que "tem capacidade de transmitir seus conhecimentos artísticos e culturais"; "e seu trabalho é reconhecido pela comunidade onde vive, como também por outros setores culturais" (PERGUNTAS FREQUENTES, 2018).

Рага o Projeto Encontro de Saberes - desenvolvido em algumas universidades brasileiras e que se propõe a convidar mestres e mestras, na condição de professores, para atuar temporariamente nas universidades, como veremos a seguir -, "mestre é uma palavra que é usada para designar aquela pessoa que se destaca no seu grupo por ser responsável e incumbida da transmissão dos saberes estruturantes nos universos culturais específicos" (INCTI, 2019, p.10). Além disso, "são sabedores reconhecidos pelas suas comunidades por sua longa trajetória e pela amplitude e densidade de seu saber; são pesquisadores, aplicam e aperfeiçoam constantemente seus saberes; ensinam o que sabem e têm discípulos, assistentes, ou seguidores" (2019, p.10). Por fim, o projeto acrescenta: "Mestres são, portanto, somente aqueles sabedores cuja senioridade é inquestionável, confirmada pela sua biografia e pelo seu reconhecimento dentro e fora de sua comunidade" (2019, p. 10).

Mais que um levantamento exaustivo, as referências acima mostram como a categoria mestre(a) tradicional vem se construindo nas últimas décadas e tem sido definida em torno de alguns critérios em comum. De forma corrente, o conceito de mestre e mestra tem sido empregado, no âmbito das políticas públicas, para identificar um conjunto de sujeitos considerados detentores, criadores e transmissores de saberes, práticas, cosmologias, técnicas, etc. relacionadas às culturas afro-brasileiras, indígenas, ao universo das culturas populares, entre outros segmentos abarcados pelo adjetivo tradicional.

Em resumo, podemos definir o conceito de mestres e mestras das culturas e/ou saberes como aqueles que são: a) detentores dos saberes, muitas vezes ancestrais, das religiões afro-brasileiras, dos povos e comunidades indígenas, quilombolas e tradicionais, assim como das práticas relacionadas ao universo das culturas populares; b) reconhecidos por suas comunidades e coletividades como possuindo um saber notório; c) responsáveis por criar e transmitir esse conhecimento. Ademais, a categoria mestre(a) discutida acima é mobilizada para traçar ações de inclusão, apoio, valorização e reconhecimento desses sujeitos considerados referências culturais e dos saberes de suas tradições. 


\section{MESTRES E MESTRAS COMO DOCENTES E A PROPOSTA DE UMA UNIVERSIDADE PLURIEPISTÊMICA}

Além de propostas de políticas públicas culturais voltadas para a valorização e apoio aos mestres(as), temos outras iniciativas com o objetivo de incluir o conhecimento desses sujeitos nos ambientes formais de ensino, como as universidades. Esse movimento de inclusão dos(as) mestres(as) no ensino formal tem acontecido como consequência de demandas que partem de diversos setores da sociedade, de diretrizes e valores expressos em leis, ações e portarias em âmbito governamental, assim como discussões teóricas internas às universidades.

Sobre a demanda de inclusão dos mestres e mestras na educação formal por parte da sociedade civil, alguns dos marcos são os I e II Seminários Nacionais de Políticas Públicas para as Culturas Populares, que ocorreram em Brasília em 2005 e 2006, respectivamente, reunindo centenas de mestres(as) de todo o Brasil. Nesses seminários, um dos encaminhamentos tirados nas plenárias finais era a inclusão dos saberes tradicionais, por meio de seus detentores, nas instituições de ensino (MINC, 2005; MINC, 2007). Outro marco, que antecede a esses seminários, foi a promulgação da Lei 10.639 de 2003, que torna obrigatório o ensino da História da África e da Cultura Afro-brasileira nas escolas. Essa lei foi substituída, em 2008, pela Lei 11.645, que passou a incluir também a história e cultura dos povos indígenas (CARVALHO, 2016). As referidas leis permitiram "um enraizamento dos currículos [escolares e universitários], em todas as nossas tradições, e não apenas nas de origem europeias" (CARVAHO, 2016, p. 6). Essas leis levaram à reivindicação para que os próprios detentores dessas culturas e saberes transmitam seus conhecimentos nesses espaços formais de ensino.

No âmbito das políticas públicas, a proposta de inclusão dos saberes tradicionais no sistema de ensino formal pode ser vista na Portaria Interministerial MEC/MINC $n^{\circ} 1$, de 4 de outubro de 2007, que estabelece as diretrizes para cooperação entre o Ministério da Cultura e o Ministério da Educação. Sobre a inclusão dos saberes tradicionais no ensino podemos encontrar referências nas diretrizes IV, "promover a formação professores, gestores, estudantes e comunidades para a valorização, reconhecimento e regulamentação dos saberes tradicionais, da diversidade étnico-racial, social e cultural e do patrimônio material e imaterial, mediante atividades que garantam resultados práticos, como publicações, audiovisuais, exposições e novas metodologias", e V, "fomentar a integração da escola e comunidade no contexto cultural nacional e internacional, mediante fóruns, encontros, seminários e outras formas de intercâmbio cultural" (BRASIL, 2007). Desenvolvendo um pouco mais esse tema, a Lei Federal $n^{\circ}$ 12.342, de 2 de dezembro de 2010, que institui o Plano Nacional de Cultura - PNC, fala em estimular a arte e a cultura no ambiente 
educacional e de reconhecer os saberes, conhecimentos e expressões tradicionais e os direitos de seus detentores. Para colocar essas diretrizes em prática, o PNC propõe a criação de políticas de transmissão dos saberes e fazeres das culturas populares e tradicionais, por meio de mecanismos como o reconhecimento formal dos mestres populares, leis específicas, bolsas de auxílio, integração com o sistema de ensino formal, criação de instituições públicas de educação e cultura que valorizem esses saberes e fazeres, criação de oficinas e escolas itinerantes, estudos e sistematização de pedagogias e dinamização e circulação dos seus saberes no contexto em que atuam (BRASIL, 2010). Em dezembro de 2013 temos ainda a Portaria Interministerial MEC/MINC no 18 (BRASIL, 2013), que institui o Programa Mais Cultura nas Universidades e o Fórum Nacional de Formação e Inovação em Arte e Cultura. No artigo $3^{\circ}$ do documento faz-se menção a discussões e ações sobre os saberes tradicionais e populares, promovendo seu reconhecimento e integração às políticas de ensino, pesquisa e extensão.

Especificamente no estado do Ceará, a Lei Estadual $n^{0}$ 16.026, de 1 de junho de 2016, que institui o Plano Estadual de Cultura do Ceará, orienta a promoção da interação, com maior periodicidade, entre os mestres diplomados (pela Lei dos Mestres que falamos no tópico anterior) e as escolas e espaços informais de educação, além de propor a outorga aos Mestres da Cultura do título de Notório Saber em artes e cultura populares, objetivando o reconhecimento de seus saberes e ofícios na prática de transmissão de seus conhecimentos.

Internamente às universidades, e numa perspectiva teórica, podemos relacionar a inclusão dos saberes tradicionais no ensino superior às críticas à colonialidade do saber, que denunciaram a perspectiva eurocêntrica e colonial da produção do conhecimento (LANDER, 2005). Esses trabalhos acadêmicos abriram margem para uma crítica à episteme que orienta a produção acadêmica, embora não tenham levado automaticamente a uma abertura de diálogos com outras tradições de conhecimento.

Especificamente sobre a relação entre o conhecimento científico e os tradicionais, Manuela Carneiro da Cunha (2009) argumenta sobre como a ciência se coloca enquanto um saber universal, válido em todas as circunstâncias, e como sua relação com os saberes tradicionais se pauta por uma concepção hierárquica - a ciência deveria desvendar, comprovar ou explicar aquilo que dizem (ou pensam dizer) os saberes tradicionais. De acordo com Boaventura de Sousa Santos e Maria Paula Meneses (2009, p. 10) essa universalização da ciência teria como consequência o "epistemicídio" - "a supressão dos conhecimentos locais perpetrada por um conhecimento alienígena" - por meio da deslegitimação e redução de outras epistemologias "como saberes locais e contextuais" e/ou "matéria prima para o avanço do conhecimento científico". Reflexões feitas nessa direção abrem possibilidades de criação de uma universidade pluriepistêmica, por meio de diálogos interdisciplinares (entre as diversas disciplinas da ciência, como propõem os estudos culturais) e transdisciplinares 
(entre a ciência e outras formas de saberes - tradicionais, quilombolas, indígenas, populares etc.) (CARVALHO, 2010).

Como resposta a essas demandas surgidas em várias dimensões, temos visto emergindo experiências de trânsito dos saberes tradicionais para os circuitos educacionais, por meio de alguns projetos, como é o caso do Encontro de Saberes, voltado para a inclusão dos mestres e mestras na docência do ensino superior.

O projeto Encontro de Saberes foi implementado em 2010, vinculado ao Instituto Nacional de Ciência e Tecnologia de Inclusão no Ensino Superior e na Pesquisa (INCTI), com sede na Universidade de Brasília. Ele procura trazer às universidades públicas, na condição de professores e pesquisadores, mestres e mestras dos saberes e das culturas, de forma a promover um diálogo e uma experiência pedagógica e epistêmica entre os saberes tradicionais e acadêmicos. Nesse sentido, o projeto Encontro de Saberes pode ser entendido como uma forma de inclusão epistêmica na docência, complementar à inclusão social e étnico-racial promovida pelas políticas de cotas nas universidades (CARVALHO, 2018).

A incorporação dos saberes tradicionais no ensino superior e na pesquisa, por meio do projeto Encontro de Saberes, até 2019 tinha irradiado da UnB para a Universidade Federal de Minas Gerais (UFMG), Universidade Federal de Pernambuco (UFPE), Universidade Federal de Juiz de Fora (UFJF), Universidade Federal do Pará (UFPA), Universidade Federal do Sul da Bahia (UFSB), Universidade Federal do Rio Grande do Sul (UFRS), Universidade Federal Fluminense (UFF), Universidade Federal do Cariri (UFCA) e Universidade Estadual do Ceará (UECE) (INCTI, 2019).

A implementação do projeto tem suas especificidades em cada universidade, mas geralmente envolve a criação de disciplinas e/ou componentes curriculares que serão ministrados por mestres(as) de diversas tradições de saberes, em parceria com um professor da universidade de área do saber afim à do(a) convidado(a) (GUIMARÃES et al., 2016; HARTMANN et al., 2019). Essas disciplinas podem ser ofertadas como obrigatórias, optativas ou eletivas, e muitas das vezes os mestres e mestras são remunerados tendo como referência a hora aula paga a professores doutores.

A maior presença dos mestres e mestras nas universidades, ministrando disciplinas e fazendo parcerias em projetos de pesquisa e produção acadêmica com os docentes dessas instituições, faz surgir desafios e demandas. Um ponto digno de destaque é que, embora os mestres e mestras ocupem o espaço de professores e sejam remunerados enquanto tal, a estrutura administrativa das universidades nem sempre permite contratá-los oficialmente como professores (seja efetivo, substituto ou visitante). Isso ocorre porque muitas das vezes os mestres e mestras não possuem trajetórias acadêmicas e/ou títulos reconhecidos institucionalmente, o que pode fazer com que sejam barrados de figurar oficialmente enquanto docentes nas universidades. Foi com vista a contornar os desafios e dar respostas a 
essas demandas que algumas universidades passam a debater a possibilidade de utilizar o título de Notório Saber como um modo de reconhecer e equiparar institucionalmente os saberes dos mestres e mestras com os acadêmicos.

\section{NotóRIO SABER E RECONHECIMENTO INSTITUCIONAL DOS SABERES DOS(AS) MESTRES(AS)}

O título de Notório Saber está presente no regimento de diversas universidades brasileiras. Em certo sentido, ele guarda relações com o título Doutor Honoris Causa, pois ambos são títulos excepcionais atribuídos pelas universidades. Contudo, ambos têm finalidades e implicações distintas. O título de Doutor Honoris Causa é atribuído a alguma personalidade que tem uma trajetória reconhecida em prol de uma causa (social, artística, política, etc.) - é um reconhecimento da universidade pelos serviços prestados à sociedade. Apesar do nome, o Doutor Honoris Causa não é equivalente ao título de doutorado acadêmico, e não habilita o sujeito agraciado a atuar e ensinar em uma universidade (CARVALHO, 2016).

O Notório Saber, por outro lado, é atribuído a alguma pessoa que não tem o título de doutorado acadêmico, mas é uma referência em alguma área e possui um conhecimento acadêmico equiparável ao de um doutor. O instrumento do Notório Saber foi utilizado pelas universidades brasileiras com dois objetivos: construir quadros para atuar nos então escassos e recém-criados cursos de pós-graduação e como forma de reconhecer docentes experientes nas universidades, mas que não possuíam o título de doutor (CARVALHO, 2016). Com a exigência quase absoluta nos concursos públicos do grau de doutorado para o ingresso na carreira do magistério superior, e com a disseminação de programas de pós-graduações nas universidades, o Notório Saber, de certa maneira, perde sua intenção original.

Atualmente, o instrumento tem voltado aos debates ao ser utilizado para reconhecer os detentores de saberes não acadêmicos, como no caso dos dos(as) mestres(as) tradicionais aqui em discussão. Como vimos, a presença desses sujeitos nas universidades brasileiras tem gerado discussões e demandas, sendo uma delas a de reconhecimento institucional dos saberes dos(as) mestres(as) por meio do Notório Saber, permitindo que eles atuem e sejam contratados enquanto docentes nas universidades - ainda que não tenham uma formação acadêmica. É importante destacar que o título de Notório Saber é um reconhecimento institucional dos saberes tradicionais, pois seus conhecimentos e maestrias já são consagrados e referenciados no contexto de suas comunidades e coletivos e, muitas das vezes, fora delas também.

Uma das primeiras experiências de reconhecimento de mestres(as) com o Notório Saber é da Universidade Federal de Santa Catarina. Apesar de não participar da rede do encontro de saberes do INCTI/UnB, a universidade titulou em 2015 o capoeirista Norival 
Moreira de Oliveira, o Mestre Nô, com o Notório Saber no campo da Educação (UFSC, 2015). A resolução sobre o Notório Saber na universidade data de 1992 (UFSC, 1992) e não faz referência específica aos mestres(as) ou formas de saberes não acadêmicas, falando apenas de pessoas com "alta qualificação científica". De acordo com a resolução, o pleiteante ao título deve atingir 160 pontos de produção acadêmica - como publicação de livros, artigos, relatórios de pesquisa, etc. Essa característica da resolução da UFSC, inclusive, foi a principal dificuldade na obtenção do título pelo Mestre Nô. De acordo com o parecer da solicitação do título, o processo voltou três vezes porque os relatores do pedido, apesar de reunir a produção e informações sobre o candidato, não fizeram a contagem de pontos da produção do mestre (que, como dito, deveria atingir no mínimo 160 pontos). Por não ter uma regulamentação específica para os mestres e mestras, os critérios adotados na resolução da UFSC tomam como modelo a pontuação de produção acadêmica, critérios alheios ao universo e dinâmicas dos saberes tradicionais (CARVALHO, 2016).

Com vista a contornar essas dificuldades, algumas universidades têm pensado e formulado propostas de resolução para o título de Notório Saber que contemplem a especificidade dos mestres, mestras e seus saberes. A experiência pioneira é a da Universidade Federal do Sul da Bahia. Criada em 2014, desde seu plano orientador a universidade coloca como tarefa promover "diálogos entre saberes científicos e humanísticos, que a universidade produz, e saberes leigos, populares, tradicionais, urbanos, camponeses, das favelas, provindos de culturas não ocidentais" (UFSB, 2014, p. 25). De um lado, tal orientação foi operacionalizada por meio da presença de mestres e contramestres de saberes tradicionais enquanto professores em componentes curriculares ofertados (TUGNY, 2020). De outro, a universidade criou, em 2015, os Graus Universitários Especiais com os títulos de Mestre em Saberes e Práticas e Doutor em Artes, Saberes e Ofícios. A resolução de criação dos títulos afirma que eles serão concedidos a:

"I. profissionais de notória especialização; II. mestres de saberes populares ou tradicionais; III. artistas de excepcional talento; IV. professores com reconhecida contribuição à Educação Básica; V. pesquisadores não-acadêmicos em campos de conhecimento científico; VI. gestores públicos com reconhecida contribuição à sociedade; VII. empreendedores de notória competência em sua área de atuação; VIII. outros casos, a critério do Conselho Universitário" (UFSB, 2015).

Cabe destaque aqui para o uso da categoria mestres de saberes populares ou tradicionais, que pela primeira vez aparece numa resolução de títulos especiais de grau acadêmico concedido por universidades. Para dar entrada ao pedido, três membros do Conselho Universitário (CONSUNI) da UFSB devem apresentar os motivos para contemplar o candidato com um dos títulos, acompanhado por memorial descritivo e outros documentos comprobatórios - a resolução não faz nenhuma menção à contagem de pontos por tipo de produção, como no caso da UFSC, relatado anteriormente. A tramitação do processo transcorre toda no CONSUNI. Os títulos especiais, ainda de acordo com a resolução, se 
restringem ao âmbito interno da UFSB, ou universidades que o reconheçam em igual medida e mediante termos de entendimentos próprios, permitindo ao contemplado:

\begin{abstract}
"I. ser convidado a participar de programas e projetos de ensino, pesquisa ou extensão na UNIVERSIDADE, devendo o convite ser feito pelo coordenador do programa ou projeto, recebendo o mesmo tratamento dispensado a um consultor ou professor visitante, sem implicar vínculo empregatício com a instituição;

II. ser eventualmente chamado a colaborar com este Conselho em deliberações que digam respeito a Saberes Práticos, Artes da Docência, Artes e Ofícios Tradicionais e Populares, diálogos interculturais ou matéria pertinente a sua particular perícia

III. encaminhar às autoridades universitárias projetos que digam respeito a sua área de conhecimento e tê-los apreciados por instância acadêmica competente;

IV. ser contratado como Professor ou Pesquisador Credenciado, nos termos do Inciso II, Art. 80 do Estatuto, observando os mesmos critérios estabelecidos para contratação de professor visitante;

V. ser recomendado por esta UNIVERSIDADE a outra instituição com fins educativos e/ou culturais a que se dirija, com o propósito de difundir seu conhecimento, saber, arte ou perícia" (UFSB, 2015, art. 5º).
\end{abstract}

Apesar da resolução, a UFSB nunca implementou de fato os Graus Especiais Universitários, e até 2020 nenhum mestre ou mestra havia sido titulado e nenhum grau especial expedido.

Posteriormente à experiência da UFSB, a Universidade Estadual do Ceará cria, em 2016, o título de Notório Saber em Culturas Populares. A UECE também fez parte da rede do Encontro de Saberes em 2014, quando ofertou uma única vez uma disciplina ministrada por mestres(as) da cura. Além da relação com o INCTI/UnB, a UECE foi atravessada pela discussão do Notório Saber devido ao contexto estadual, especificamente por causa da Lei dos Mestres (CEARÁ, 2006) e do Plano Estadual de Cultura (CEARÁ, 2016). Entre outras coisas, o Plano Estadual de Cultura do Ceará (CEARÁ, 2016) propõe à "Universidade Estadual do Ceará a outorga aos Mestres da Cultura o Título de Notório Saber em artes e cultura populares, objetivando o reconhecimento de seus saberes e ofícios na prática de transmissão de seus conhecimentos" (CEARÁ, 2016).

Foi a partir dessa demanda e de uma posterior parceria da UECE com a SECULT (CE) que a universidade passa a certificar com o Notório Saber mestres e mestras. A UECE conta com uma resolução para o Notório Saber desde 2011 (UECE, 2011), posteriormente atualizada em 2014 (UECE, 2014). A titulação prevista na resolução se dá por áreas e o título é expedido pela Pró-Reitoria de Pós-Graduação e Pesquisa. Não havia previsão, na resolução de 2014, de contemplar mestres e mestras com o título. De forma, então, a atender a demanda da SECULT (CE), a UECE aprova uma nova resolução em 2016, que existe em paralelo à resolução de 2014, e que dispõe sobre as normas para a outorga do título de Notório Saber em Cultura Popular (UECE, 2016). A resolução é voltada exclusivamente para os mestres e mestras diplomados pela Lei dos Mestres estadual. Para dar entrada no pedido deverá constar uma carta circunstanciada da indicação por parte da UECE ou da SECULT (CE), histórico de vida do candidato e documento que comprove o título de mestre da cultura, 
emitido pela SECULT (CE). Esses documentos são analisados por comissão constituída pela Pró-Reitoria de Extensão, o parecer da comissão votado na Câmara de Extensão da universidade, e o certificado correspondente ao título de Notório Saber expedido pela PROEX. Na resolução não existe nenhuma explicação quanto às consequências do título, tanto no âmbito interno, quanto externo da universidade. De todo modo, em 2016, logo após a aprovação da resolução, foram reconhecidos 58 mestres e mestras, e em 2020 já são mais de 80 os certificados.

No ano de 2019, temos a experiência de mais duas universidades que aprovam uma resolução com vista a atribuir o título de Notório Saber ou grau especial universitário aos mestres e mestras, a Universidade de Sergipe e a Universidade de Pernambuco. A UFS aprovou a resolução que regulamenta a concessão de Grau de Mérito Universitário Especial em junho de 2019, criando dois títulos, o Grau de Mérito em Saberes e Fazeres e o Grau de Mérito em Artes e Culturas Populares (UFS, 2019). De acordo com a resolução os títulos serão concedidos a "pessoas não detentoras de título acadêmico, de graduação e de pósgraduação, desde que comprovem destacada experiência e produção nos diferentes saberes, fazeres e linguagens de todas as áreas de conhecimento, popular e tradicional, e, ter competência e reconhecimento social demonstrados no campo das Artes e Cultura Popular em seu histórico de vida" (UFS, 2019, p. 2). Рara pleitear o título, o candidato deve se inscrever nos editais anuais que serão lançados pela PROEX (PROEX/UFS, 2020). No momento da inscrição no edital o candidato apresenta, entre outros documentos, uma descrição e história da sua trajetória, com suas respectivas comprovações que podem assumir formas heterogêneas (fotos, vídeos, gravações, entrevistas). Posteriormente, uma comissão irá analisar essas candidaturas, por meio do preenchimento de uma ficha de avaliação, que contempla determinados requisitos e critérios, e elaborar um parecer (PROEX/ UFS, 2020). Cabe destaque aqui para a novidade na composição dessa comissão examinadora. Além da vice-reitoria, pró-reitor de extensão, docentes e pesquisadores da UFS e externos, a comissão também prevê um representante do Conselho Estadual de Cultura, um representante do IPHAN, e um representante da Fundação de Cultura Aperipê. Aqui, pela primeira vez, outras instituições, com destacada atuação no setor das políticas culturais no estado do Sergipe, são envolvidas no processo de reconhecimento das candidaturas a títulos especiais universitários. Sobre as consequências do título, ele tem validade no âmbito interno da UFS, ou universidades que o aceitem em igual medida, e permite ao contemplado atuar na UFS nos mesmos âmbitos previstos pela resolução da UFSB, referenciado acima.

No final do mesmo ano, a UPE, universidade estadual de Pernambuco, aprova a criação do título de Notório Saber em Cultura Popular (UPE, 2019). Segundo a resolução, o título poderá ser concedido a pessoas com "destacada experiência e produção em, pelo menos, uma das linguagens ou áreas da arte e da cultura popular, incluindo-se as categorias 
evidenciadas no campo do patrimônio imaterial segundo os critérios da Convenção para a Salvaguarda do Patrimônio Cultural Imaterial - UNESCO e/ou tenham conquistado o título de Patrimônio Vivo do Estado de Pernambuco". Cabe destacar aqui a referência a documentos e legislações do patrimônio imaterial estaduais - como é o caso da Lei no 12.196, que institui o registro do Patrimônio Vivo do Estado do Pernambuco e da definição de Tesouro Vivo (PERNAMBUCO, 2002) - e internacionais - como é o caso da convenção de 2003 da UNESCO. Essas referências explicitam um diálogo entre a resolução do título com o campo das políticas culturais. A candidatura ao Notório Saber em Cultura Popular pode ser feita pela sociedade civil ou pela Fundação do Patrimônio Histórico e Artístico de Pernambuco (UPE, 2019). Entre os documentos solicitados estão um histórico ou memorial de vida do candidato. A abertura do processo da candidatura é feita através da Pró-Reitoria de Extensão e Cultura. Em 2020 foi lançado um edital para a inscrição das candidaturas em período específico (PROEC/UPE, 2020), apesar do edital não estar previsto na resolução. Após receber a candidatura se institui uma comissão com três nomes indicados pela PROEC/UPE para emitir um parecer - a composição dessa comissão, contudo, não é discriminada na resolução. As consequências do título, assim como na experiência da UECE, não são discriminadas na resolução da UPE ou no edital lançado em 2020.

Por fim, temos o caso recente da UFMG, outra universidade da rede do Encontro de Saberes e instituição aonde a presença dos mestres e mestras como professores mais se expandiu. É importante destacar que a UFMG "possui um significativo histórico de protagonismo em ações de reconhecimento e inclusão dos mestres de saberes tradicionais em suas instâncias de produção e compartilhamento de saber" (GUIMARÃES et al, 2016, p. 183). Contudo, especificamente sobre a proposta de atuação dos mestres e mestras enquanto professores em disciplinas, esta tem início em 2014, com a criação do componente curricular Artes e Ofícios dos Saberes Tradicionais, ofertado pela Comunicação Social. Posteriormente foi apresentado um projeto à Pró-Reitoria de Graduação de tornar permanente a oferta da disciplina, por meio da sua inclusão como um dos eixos da Formação Transversal, o de saberes tradicionais. Desde então disciplinas ministradas por mestres e mestras têm sido ofertadas regularmente.

No referido projeto citado acima, apresentado à PROGRAD da UFMG, entre os objetivos se encontrava também o desejo de "titulação dos mestres com Notório Saber com base numa discussão qualificada com setores diversos da sociedade, como o IPHAN, o INCT de Inclusão, o MINC, o CNPq e pesquisadores envolvidos com o tema" (GUIMARÃES et al, 2016, p. 192). Essa discussão iniciada em 2014 culminou na aprovação da regulamentação do reconhecimento do Notório Saber, por meio da Resolução Complementar 01/2020 (UFMG, 2020). A resolução não trata exclusivamente da concessão do título para mestres e mestras, 
mas deixa explícito que pode contemplar esses sujeitos, como aponta o artigo terceiro do documento:

"Poderão ser reconhecidos, para efeito desta Resolução, saberes acadêmicos, científicos, artísticos e culturais já presentes da Universidade, e de outras tradições científicos e artísticos e culturais, tais como indígenas, afro-brasileiros, quilombolas, das culturas populares e demais tradições" (UFMG, 2020).

Ainda, de forma a atender a especificidade desses sujeitos, a resolução fala da exigência de memorial descritivo do postulante, comprovando pelo menos 20 anos de atuação na área de conhecimento em que se pede o Notório Saber - o documento não precisa ser redigido pelo postulante.

Neste caso, o pedido de reconhecimento deve ser feito por um colegiado de Curso de Pós-Graduação à Câmara de Pós-Graduação. Posteriormente, constitui-se uma comissão para avaliar o pedido e emitir um parecer que será votado no Conselho de Ensino, Pesquisa e Extensão (CEPE). Em caso de aprovação no CEPE, a Pró-Reitoria de Pós-Graduação expede o diploma na área de saber correspondente. O título de Notório Saber será expedido apenas nas áreas que a universidade tenha curso de doutorado. Isso ocorre porque no entendimento da Lei das Diretrizes Básicas da Educação (BRASIL, 1996), o Notório Saber, para equivaler ao grau de doutorado, deverá ser reconhecido por universidade com curso de doutorado em área afim. No caso da resolução da UFMG, ela é a única a dizer literalmente que o Notório Saber equivale ao grau de doutorado acadêmico. Por se tratar de uma resolução nova, nenhum mestre ou mestra foi titulado, mas existe um trabalho intenso que fará com que ao longo de 2021 os pedidos sejam apreciados no CEPE.

A partir das resoluções e experiências abordadas, que dizem respeito ao Notório Saber que contemplem explicitamente mestres e mestras - UFSB, UECE, UFS, UPE e UFMG -, podemos traçar algumas tendências, questões e reflexões. O primeiro ponto de aproximação entre elas, é que todas dialogam com a categoria mestres e mestras dos saberes tradicionais. No caso das resoluções da UECE, UFSB, UPE e UFS a referência ao termo mestre(a) é direto, mas na UFMG ele também é contemplado quando a resolução se refere aos saberes de outras tradições culturais. Um segundo ponto é a adoção do formato memorial descritivo (UFMG, UFSB e UPE), ou história de vida (no caso da UECE e UFS), como uma forma de comprovação do direito ao título. Esse formato permite a avaliação do postulante dentro de sua própria lógica de produção de conhecimento - em oposição à experiência do Mestre Nô na UFSC, que teve sua trajetória quantificada por meio de um sistema de pontuação próprio da academia.

Se essas resoluções se aproximam nos pontos acima, elas diferem em outros aspectos importantes. A primeira diferença diz respeito ao trâmite administrativo. No caso da UFSB, a circulação do pedido de Notório Saber se restringe exclusivamente ao CONSUNI, que recebe o pedido, constitui comissão e vota o parecer. Por um lado, esse trâmite parece 
garantir maior celeridade ao processo. Porém, ele não envolve outras pró-reitorias, colegiados de cursos, etc. nas discussões - com a ressalva de que o CONSUNI é um órgão bastante diverso em termos de representatividade. No caso da UECE, UFS e UPE o trâmite se dá exclusivamente na PROEX (ou PROEC, no caso da UPE) e na Câmara de Extensão (UECE e UPE) ou Conselho Universitário (UFS). Esse modelo tem como ponto positivo o fato das próreitorias de extensão terem um maior vínculo com a dita "comunidade externa", porém, ele mantém uma interlocução exclusiva com a PROEX, não envolvendo outras pró-reitorias nos trâmites administrativos da candidatura, principalmente aquelas ligadas à graduação, pósgraduação e pesquisa. Apesar disso, as resoluções da UECE, da UPE, UFS articulam-se com outras instituições, como secretarias de culturas estaduais, instituições ligados ao patrimônio e a políticas culturais, de modo geral.

Na experiência da UFMG essa discussão se dá no âmbito da Pós-Graduação, por meio de colegiados de curso, pró-reitorias e câmaras. Uma das vantagens desse modelo é que ele estimula que essas instâncias administrativas de ensino e pesquisa discutam e se envolvam nos processos de titulação dos mestres e mestras pelo Notório Saber.

Por fim, e talvez o ponto mais importante, uma última diferença é a área na qual o título é expedido. No caso da UECE, UPE, UFS e UFSB se optou por criar novas áreas para o título: nas duas primeiras o Notório Saber em Cultura Popular, nas duas últimas os graus especiais em Saberes e Fazeres/Práticas e Artes, Saberes e Ofícios/Cultura Popular. Por um lado, esse modelo (que cria uma área do Notório Saber ou Grau Especial) tem um maior potencial de tradução dos saberes dos mestres e mestras devido ao seu aspecto transdisciplinar. Porém, os títulos nessas áreas têm algumas limitações, pois dificilmente as universidades, em seus concursos e contratações de docentes, aceitam o título nessas novas áreas criadas. Somado a isso, tanto no caso da UECE como na da UPE, as resoluções não preveem a inclusão dos contemplados com o título no âmbito do ensino, pesquisa e extensão das respectivas universidades. Cabe destacar, porém, que no caso da UFS e UFSB o efeito desses títulos expedidos se voltam exclusivamente para a atuação dos contemplados no âmbito do ensino, pesquisa e extensão das universidades que os expediram. É claro, isso não impede que as universidade brasileiras passem a prever a aceitação do título nessas novas áreas de Notório Saber criadas - essa possibilidade é inclusive sugerida nas resoluções que adotam a expressão: "a validade do título é de âmbito interno à universidade, ou universidades que os aceitem em igual medida".

No caso da UFMG, o título de Notório Saber é expedido em alguma área em que a universidade tem curso de doutorado, e equivale explicitamente a um diploma de doutorado. Nesse caso do título expedido em grandes áreas de saberes reconhecidas pelas instituições que regulamentam a pós-graduação no Brasil, essa integração ao sistema de ensino superior é mais potente e integral, não necessitando que a resolução preveja os 
âmbitos de atuação do contemplado - pois as implicações são as mesmas do que para qualquer recém doutorado.

Contudo, além das potencialidades e limitações em relação a um ou outro modelo, é preciso se atentar aos contextos e realidades de cada universidade na adoção desses diferentes caminhos e estratégias para a criação do título. De forma a explicitar como essas resoluções devem ser percebidas a partir do seu contexto de aprovação, no tópico a seguir será feito um relato da experiência de redação da resolução do Notório Saber em Artes, Ofícios e Cosmologias Tradicionais na Universidade da Integração Internacional da Lusofonia Afro-Brasileira.

\section{UMA PROPOSTA DE NOTÓRIO SABER EM ARTES, OfícIOS E COSMOLOGIAS TRADICIONAIS NA UNILAB}

Levando em conta o levantamento e as reflexões acima, foi redigido no âmbito da comissão para a realização de estudos técnicos de viabilização do reconhecimento do notório saber dos mestres da cultura popular na UNILAB, instituída em agosto de 2020, uma minuta de resolução de Notório Saber em Artes, Ofícios e Cosmologias Tradicionais. Essa minuta foi apresentada para a Reitoria, instituições parceiras, como a Secretaria de Cultura do Ceará (SECULT-CE) e o Instituto do Patrimônio Histórico e Artístico Nacional (IPHAN), e encaminhada para a Câmara de Extensão para parecer técnico da viabilidade e legalidade da minuta. Posteriormente a minuta foi votada no CONSEPE e aprovada no dia 11 de fevereiro de 2021 por unanimidade. Desde $1^{\circ}$ de março do mesmo ano a resolução está em voga, e algumas apresentações sobre a resolução e seus desdobramentos têm sido feitas nos diversos institutos da universidade. Neste tópico irei falar sobre o processo de construção da minuta no contexto específico da UNILAB e seus potenciais desdobramentos.

A respeito da minuta de resolução do Notório Saber, até a forma final apresentada a proposta teve diversas redações. Em um primeiro momento, se pensou em tomar como modelo a experiência da UFMG, pois era a única que equiparava, sem sombras de dúvidas, o Notório Saber ao grau de doutorado acadêmico e promovia uma integração mais completa com o circuito do ensino superior.

Contudo, a realidade da UNILAB é muito diferente da UFMG. A UNILAB tem apenas pouco mais de uma década de existência, e ainda não possui cursos de pós-graduação a nível de doutorado - apenas oito cursos de mestrado nas áreas de humanidades, letras, saúde, pedagogia, matemática e meio ambiente e energia. Diante deste contexto e o consequente risco da resolução se tornar uma letra morta se aprovada a partir do modelo da UFMG, optamos por nos aproximar do caminho das outras universidades referidas anteriormente UECE, UFSB, UFS e UPE - ainda que alguns artigos e procedimentos da resolução da UFMG 
tenham nos servido de inspiração. Ainda, a minuta procurou dialogar com o campo das políticas culturais e educacionais, enfatizando categorias como mestres e mestras e temas como valorização do patrimônio cultural e inclusão dos saberes tradicionais no circuito da educação formal ${ }^{4}$.

O nome do título previsto na resolução ficou acordado em Notório Saber em Artes, Ofícios e Cosmologias Tradicionais. A opção pelas categorias artes, ofícios e cosmologias que compõem a nomenclatura do certificado se deu pois elas fazem referência às diversas linguagens e "áreas" dos saberes tradicionais, assim como guardam a possibilidade de agregar (por causa do termo tradicional) uma heterogeneidade de sujeitos ligado às "culturas indígenas, quilombolas, de comunidades de terreiro, de comunidades de agricultores e extrativistas, agrupamentos rurais e urbanos em torno de tradições populares, entre outras tradições brasileiras e da Comunidade de Países de Língua Portuguesa (CPLP), em especial os africanos" (CONSEPE/UNILAB, 2021, art. $\left.2^{\circ}\right)^{5}$. Nesse sentido, a resolução se aproxima das experiência da UFSB, UECE, UFS e UPE, ao criar uma área do saber. A limitação dessa escolha, como já vimos, é que ela não habilita automaticamente que os(as) mestres(as) atuem nas universidades como professores, mas voltaremos a esse tema de forma mais aprofundada à frente.

Para que um(a) candidato(a) seja contemplado(a) com o Notório Saber em Artes, Ofícios e Cosmologias Tradicionais, é preciso que ele(a) se constitua como um mestre(a) das culturas e dos saberes, assim considerados a partir de três critérios:

"a) reconhecidos como referências em determinada área do saber e da cultura por suas comunidades, coletivos e/ou agrupamentos;

b) responsáveis por guardar, criar e transmitir esses saberes, contribuindo para a continuidade das artes, ofícios e cosmologias tradicionais;

c) com destacada experiência e atuação de no mínimo 20 anos em determinada área do saber ou da cultura, dentro e fora de suas comunidades, coletivos ou agrupamentos" (CONSEPE/UNILAB, 2021, art. $3^{\circ}$ ).

Como podemos perceber, esses critérios foram construídos a partir do diálogo com legislações de proteção aos mestres(as), por entendimentos convencionados no âmbito do projeto Encontro de Saberes e inspiração em outras resoluções aqui discutidas. Рara comprovar os critérios é exigido um "memorial descritivo escrito [...] abrangendo sua biografia e [...] 20 (vinte) anos de atuação" no âmbito das artes, ofícios e/ou cosmologias tradicionais, "devidamente comprovado por documentação escrita, fílmica, jornalística, sonora, visual, audiovisual, fotográfica, englobando também correspondências, diários, testemunhos, relatos, portfólio, dentre outros" (CONSEPE/UNILAB, 2021, art. 5º).

\footnotetext{
${ }^{4}$ Uma discussão sobre as legislações, resoluções, portarias, etc. que nos serviram de inspiração foi realizada na segunda parte deste artigo.
}

${ }^{5}$ Neste trecho citado cabe destacar a inspiração na resolução da UFMG, de 2020. 
Do ponto de vista administrativo, como a provocação para a criação do título se deu por parte da Coordenação de Arte e Cultura, vinculada à PROEX, o trâmite do processo de emissão do certificado se inicia em tal pró-reitoria e é ela quem assina a certificação do Notório Saber, em conjunto com a reitoria, ao final do processo. Apesar disso, a emissão do parecer sobre o pleito ao título é realizada por uma Comissão de Avaliação de Mérito, que depois o encaminha para votação no Conselho de Ensino, Pesquisa e Extensão (CONSEPE) órgão que conta com representatividade de diversas categorias da comunidade acadêmica. Ainda, a resolução prevê o recebimento de candidaturas para o título em caráter de fluxo contínuo, optando por não adotar o modelo de lançamento de edital, como ocorre na UFS e UPE, por entendermos que o edital promove a concorrência dos mestres e mestras entre si o que não é nosso objetivo ${ }^{6}$.

No âmbito da Comissão de Análise de Mérito buscamos como inspiração as resoluções da UFS e UPE. Nesse sentido, a resolução para o reconhecimento dos mestres e mestras na UNILAB se dá por meio de parceria interinstitucional entre a universidade, SECULT (CE) e IPHAN. A parceria com essas instituições existe desde 2016 por meio de Acordos de Cooperação Técnica. No caso da SECULT (CE) esse acordo envolve o desenvolvimento de ações de intercâmbio entre as instituições, sem delimitação de área ou objetivos específicos de atuação. O acordo de cooperação com o IPHAN, superintendência do Ceará, por sua vez, foi feito no âmbito da Salvaguarda da Capoeira do Ceará, e previa, entre outras coisas, estudos e discussões para o reconhecimento dos mestres de capoeira por meio do Notório Saber na universidade. Desse modo, as duas instituições têm papel na resolução, especificamente na Comissão de Análise de Mérito. No caso do IPHAN, ele deve indicar um técnico para compor a comissão, enquanto a SECULT (CE) deverá indicar um mestre reconhecido pela Lei dos Mestres estadual (CEARÁ, 2006) para compor a mesma comissão. A participação dos mestres e mestras visa envolver parcela dos sujeitos desse universo, com bom trânsito e reconhecimento no campo das políticas culturais, na avaliação de outros mestres e mestras. Nesse sentido, a análise de mérito dos candidatos ao título não se concentra apenas em representantes do setor acadêmico e técnicos de instituições de cultura.

Outra especificidade que merece destaque na resolução é a possibilidade de reconhecer na Comunidade de Países de Língua Portuguesa (CPLP), em especial os africanos, pessoas análogas aos mestres e mestras. Como sabemos, a UNILAB é uma universidade que tem como projeto a internacionalização, principalmente no âmbito da CPLP e,

\footnotetext{
${ }^{6}$ Cabe ponderar, contudo, que apesar das resoluções da UPE e da UFS adotarem editais, nesses editais não existe previsão de número mínimo ou máximo de pessoas que podem ser contempladas, minimizando o caráter competitivo dos mesmos.
} 
particularmente, com seus membros do continente africano. Foi articulando essa missão institucional da UNILAB que a previsão de reconhecimento com o Notório Saber de pessoas de outros países foi concebida. Pelo caráter inovador é preciso acompanhar como esse diálogo irá ocorrer, visto que nem em todos os lugares se entende a palavra mestre(a) relacionada como aquele(a) que guarda, desenvolve e transmite o conhecimento - em alguns contextos esses papéis são desempenhados por diferentes sujeitos.

A respeito das implicações do título, ainda que o contemplado não seja reconhecido enquanto o equivalente a um professor doutor pelo sistema de ensino superior, a resolução tem implicações no âmbito interno da UNILAB. Desse modo, a resolução prevê que o contemplado possa atuar nos âmbitos de ensino, pesquisa e extensão - prevendo, inclusive, sua contratação na categoria de professor visitante:

"Art. $10^{\circ}$ O detentor do título de Notório Saber em Artes, Ofícios e Cosmologias Tradicionais poderá:

a) ser convidado a participar de programas, projetos e atividades de ensino, pesquisa ou extensão na Universidade da Integração Internacional da Lusofonia Afro-Brasileira, sem implicar vínculo empregatício com a instituição;

b) encaminhar às autoridades universitárias projetos que digam respeito à sua área de conhecimento, desde que em parceria com docente da Universidade da Integração Internacional da Lusofonia Afro-Brasileira, e tê-los apreciados por instância acadêmica competente;

c) ser contratado como Professor Visitante, nos termos do artigo $78, \S 3^{\circ}$ do Regimento Geral da UNILAB, da Lei Federal $n^{\circ} 12.772(28 / 12 / 2012)$ e da Lei Federal $n^{\circ}$ 8.745 (09/12/1993)" (CONSEPE/UNILAB, 2021).

Além disso, a resolução deixa em aberto que outras universidades possam vir no futuro a reconhecer o título emitido pela UNILAB, ao prever que, apesar do título ter "validade no âmbito interno da universidade", nada impede que outras instituições "os reconheçam em igual medida, mediante termos de entendimento próprios" (CONSEPE/UNILAB, 2021, art. $9^{\circ}$ ).

Cabe ressaltar que a aprovação da resolução sozinha não é garantia de inclusão epistêmica dos saberes tradicionais na UNILAB. Ela é sim um passo importante, mas que deve vir junto com uma observação dos processos de titulação do Notório Saber nas diferentes etapas, assim como discussões sobre seus desdobramentos e consequências. Nesse sentido, é preciso acompanhar como irão funcionar as comissões de análise de mérito que comportam acadêmicos, mestres e técnicos de instituições culturais. Ainda, pelo fato da UNILAB ser uma universidade com campus fora de sede - o campus dos Malês, em São Francisco do Conde (BA) - é preciso incorporar outras instituições no processo como a Secretaria de Cultura da Bahia, o Instituto do Patrimônio Cultural da Bahia, assim como as secretarias de cultura ou similares em âmbito municipal. Esse reajuste poderá ser feito no futuro, inclusive, por meio de ajustes na redação da resolução ou outras formas de incorporar essas instituições sem precisar necessariamente mexer no desenho da mesma. 
Além disso, é preciso incluir esses mestres e mestras titulados como professores(as) em disciplinas existentes, e/ou a criação de novas disciplinas aonde eles(as) possam atuar. Um primeiro movimento em tal direção foi feito com a criação e oferta de uma disciplina que teve como convidados mestres ou mestras dos saberes tradicionais de várias partes do Brasil. A disciplina ocorreu no Período Letivo Excepcional, ofertada no segundo semestre de 2020 pelo curso de Bacharelado em Antropologia, do Instituto de Humanidades. O componente curricular Mestra(e)s das culturas e o Encontro de Saberes, ocorreu de forma totalmente virtual, como consequência da pandemia de COVID-19, por meio de seminários semanais com professores(as) e mestres(as) convidados(as), com o intuito de debater a inclusão epistêmica nas universidades. Além de alunos e alunas da UNILAB, parte da programação da disciplina foi aberta ao público, ofertada também como um seminário. Contudo, é preciso institucionalizar essas experiências na grade curricular da universidade enquanto disciplinas abertas a todos os cursos e garantir remuneração aos mestres e mestras que atuarem como docentes nas disciplinas. Outro ponto da atuação dos mestres e mestras passa pela criação de previsão regimental para que eles(as) possam participar de bancas de defesa de TCC e Dissertações nos mais variados cursos e programas da universidade. Por fim, é necessário acompanhar de perto os efeitos desses diferentes processos para os mestres, mestras, seus saberes e suas comunidades e coletivos.

Como vimos, a discussão sobre o Notório Saber apresentada acima é produto da emergência da categoria mestres(as) tradicionais nas políticas públicas e da inclusão desses sujeitos na rede de ensino formal. Sobre as experiências de titulação dos mestres e mestras com o Notório Saber, apesar de ainda tímidas, elas têm se tornada cada vez mais numerosas. O debate sobre o tema tem mobilizado mestras(es), professoras(es), alunas(os), pró-reitorias, instâncias deliberativas das universidades, secretarias de cultura, etc. Nesse contexto, observamos algumas tendências, desafios e caminhos trilhados pelas universidades com vista a concretizar um reconhecimento institucional dos detentores dos saberes tradicionais e promover a inclusão epistêmica.

Diante das tendências e modelos de resoluções de Notório Saber discutidas aqui, a regulamentação do Notório Saber em Artes, Ofícios e Cosmologias Tradicionais, é uma forma da UNILAB tomar parte nesse debate mais geral. Dessa maneira, a minuta de resolução procura atender a uma demanda dos mestres(as) e seus coletivos, das políticas e diretrizes culturais em âmbito estadual e federal e do esforço rumo a uma universidade pluriepistêmica. Apesar de ser um passo importante, a resolução é apenas um primeiro passo rumo ao projeto de inclusão dos(as) mestres(as) como docentes nas nossas universidades e à sua transformação epistêmica. 


\section{REFERÊNCIAS}

ABREU, Regina. "Tesouros humanos vivos" ou quando pessoas se transformam em patrimônio cultural - notas sobre a experiência francesa e a distinção do "Mestres da Arte". In: ABREU, Regina; CHAGAS, Mário. Memória e Patrimônio: ensaios contemporâneos. Rio de Janeiro: ed. Lamparina, 2009. p. 34-48.

ALMEIDA, Mauro; CUNHA, Manuela Carneiro da. Populações tradicionais e conservação ambiental. In: CUNHA, Manuela Carneiro da. Cultura com aspas. São Paulo: Cosac Naify, 2009. p. 277-300.

BRASIL. Lei n 9.394/1996. Estabelece as diretrizes e bases da educação nacional. Diário Oficial da União, Brasília, 1996.

BRASIL. Portaria Normativa Interministerial MINC/MEC $n^{0}$ 1/2007. Estabelece as diretrizes para cooperação entre o Ministério da Cultura e o Ministério da Educação. Diário Oficial da União, Brasília, 2007.

BRASIL. Câmara dos Deputados. Projeto de Lei 1.176-B/2011. Institui o Programa de Proteção e Promoção dos Mestres e Mestras dos saberes e fazeres das culturas populares. Brasília, DF, 2011.

BRASIL. Lei $n^{0}$ 12.343/2010. Institui o Plano Nacional de Cultura - PNC, cria 0 Sistema Nacional de Informações e Indicadores Culturais - SNIIC e dá outras providências. Diário Oficial da União, Brasília 2010.

BRASIL. Portaria Interministerial $n^{0}$ 18/2013. Institui o Programa Mais Cultura nas Universidades e 0 Fórum Nacional de Formação e Inovação em Arte e Cultura. Diário Oficial da União, Brasília, 2013.

CARVALHO, José Jorge de. Los estudios culturales en América Latina: Interculturalidad, acciones afirmativas y encuentro de saberes. Tabula Rasa, Colômbia, n. 12, p. 229-251, 2010.

CARVALHO, José Jorge de. Sobre o Notório Saber dos mestres tradicionais nas instituições de ensino superior e de pesquisa. Cadernos de Inclusão, Brasília, n.8, 2016.

CARVALHO, José Jorge de. Encontro de Saberes e descolonização: para uma refundação étnica, racial e epistêmica das universidades brasileiras. In: BERNADINO-COSTA, Joaze; MALDONADO-TORRES, Nelson; GROSFOQUEL, Ramón (org.). Decolonialidade e pensamento afrodiapórico. Belo Horizonte: Ed. Autêntica, 2018. p. 79-106.

CEARÁ. Lei 13.351/2003. Institui o Registro dos Mestres da Cultura Tradicional Popular do Estado do Ceará. Diário Oficial Estadual, Fortaleza, 2003.

CEARÁ. Lei 13.842/2006. Institui o registro dos "tesouros vivos da cultura" no estado do Ceará e dá outras providências Diário Oficial Estadual, Fortaleza, 2006.

CEARÁ. Lei 16.026/2016. Institui o Plano Estadual de Cultura. Diário Oficial Estadual, Fortaleza, 2016.

CUNHA, Manuela Carneiro da. Relações e dissenções entre saberes tradicionais e saber científico. In: CUNHA, Manuela Carneiro da(Org.). Cultura com aspas. São Paulo: Cosac Naify, 2009. p. 301-310. 
GUIMARÃES, César; et al. Por uma universidade pluriepistêmica: a inclusão de disciplinas ministradas por mestres dos saberes tradicionais e populares na UFMG. Tessituras, Pelotas, v. 4, $n^{0} 2$, p. 179-201, 2016.

HARTMANN, Luciana; et al. Tradição e tradução de saberes performáticos nas universidades brasileiras. Repertório, Salvador, v. 22, n. 33, p. 8-30, 2019.

IKEDA, Alberto T. Culturas Populares no Presente: fomento, salvaguarda e devoração. Estudos Avançados, São Paulo, v. 27, n. 79, p. 173-190, 2013.

INCTI. Encontro de Saberes nas Universidades: atualização 2010-2018. Brasília: INCTI/UnB/CNPq, 2019.

LANDER, Edgardo (org.). A colonialidade do saber: eurocentrismo e ciências sociais: perspectivas latino-americanas. Buenos Aires: CLACSO, 2005.

MINC. Anais do I Seminário Nacional de Políticas Públicas para as Culturas Populares. São Paulo/Brasília: Inst. Polís/MinC, 2005.

MINC. Anais do II Seminário Nacional de Políticas Públicas para as Culturas Populares/ I Encontro SulAmericano das Culturas Populares. São Paulo/Brasília: Inst. Polís/MinC, 2007.

PERGUNTAS FREQUENTES. Prêmio Culturas Populares. Ministério da Cultura, Brasília, s/d. Disponível em: <http://culturaspopulares.cultura.gov.br/perguntas-frequentes/> Acesso em: 24 de julho de 2018.

PERNAMBUCO. Lei $n^{0}$ 12.196, de 2 de maio de 2002, que institui, no âmbito da Administração Pública Estadual, o Registro do Patrimônio Vivo do Estado de Pernambuco - RPV-PE, e dá outras providências. Diário Oficial Estadual, Recife, 2002.

PROEC/UPE. Edital Extensão 03/2020 - Título de Notório Saber em Cultura Popular. PROEC, Recife, 2020.

PROEX/UFS. Edital PROEX RAEX N05/2020, de 26 de maio de 2020, concessão do Grau de Mérito Universitário Especial em Saberes e Fazeres e em Artes e Culturas Populares. PROEX, Sergipe, 2020.

SANTOS, Boaventura de Souza; MENESES, Maria Paula. Introdução. In: SANTOS, Boaventura de Souza; MENESES, Maria Paula (Orgs.) Epistemologias do Sul. Coimbra: CES, Edições Almedina, 2009. p. 9-20.

TUGNY, Rosângela Pereira de. Conhecimentos tradicionais e território na formação universitária. In: TUGNY, Rosângela Pereira de; GONÇALVES, Gustavo (orgs.). Universidade Popular e Encontro de Saberes. Salvador: EDUFBA; Brasília: INCTI/UNB, 2020. p. 439-462.

UECE. Resolução nº 822/2011: baixa normas para a outorga do título de Notório Saber, da Universidade Estadual do Ceará - UECE. CONSU, Fortaleza, 2011.

UECE. Resolução $n^{0}$ 1092/2014: dispõe sobre as normas para a outorga do título de Notório Saber pela Universidade Estadual do Ceará - UECE. CONSU, Fortaleza, 2014.

UECE. Resolução $n^{0}$ 1.194/2016: dispõe sobre as normas para a outorga do título de Notório Saber em Cultura Popular pela Universidade Estadual do Ceará - UECE. CONSU, Fortaleza, 2016. 
UFMG. Resolução complementar $n^{0}$ 01/2020, de 28 de maio de 2020. In: Boletim, Belo Horizonte, n² 2091, ano 46, edição especial, 2020.

UFS. Resolução $n^{0}$ 04/2019, regulamenta a concessão de Grau de Mérito Universitário Especial no âmbito da Universidade Federal de Sergipe. CONSEPE, Aracaju, 2019.

UFSB. Plano Orientador. Itabuna, Porto Seguro, Teixeira de Freitas: UFSB, 2014.

UFSB. Resolução 17/2015: regulamente a concessão de Graus Universitários Especiais no âmbito da Universidade. Reitoria, Itabuna, 2015.

UFSC. Processo n² 23080.014870/2015-11: parecer. Reitoria, Florianópolis, 2015.

UFSC. Resolução $n^{0}$ 55/CEPE/1992. Dá uma nova redação à resolução $n^{\circ}$ 006/CEPE/86, que regulamente o Notório Saber. Reitoria, Florianópolis, 1992.

UNESCO. Convenção de 2003 para a Salvaguarda do Patrimônio Cultural Imaterial. UNESCO, Paris, 2003

UNILAB. Resolução $n^{0}$ 53, De 11 de fevereiro de 2021, que aprova a criação do título de Notório Saber em Artes, Ofícios e Cosmologias Tradicionais e regulamenta a expedição do certificado no âmbito da Universidade da Integração Internacional da Lusofonia Afro-Brasileira. CONSEPE, Redenção, 2021.

UPE. Resolução CONSUN nº 023/2019, regulamente a outorga do título de Notório Saber em Cultura Popular pela Universidade de Pernambuco. CONSUN, Recife, 2019.

Recebido em 31 de agosto de 2020. Aprovado em 22 de novembro de 2021. 